\title{
Additional Reserve Recovery Using New Polymer Treatment on High Water Oil Ratio wells in Alameda Field, Kingman County, Kansas
}

Final Technical Report

March 17, 2003 - May 16, 2004

James Spillane

Report Issued October 2005

DE-FG26-03NT15433

Crystal River Oil \& Gas, LLC

169Saxony, Suite 212

Encinitas, CA 92024

\begin{abstract}
Disclaimer
"This report was prepared as an account of work sponsored by an agency of the United States Government. Neither the United States Government nor any agency thereof, nor any of their employees, makes any warranty, express or implied, or assumes any legal liability or responsibility for the accuracy, completeness, or usefulness of any information, apparatus, produce, or process disclosed, or represents that its use would not infringe privately owned rights. Reference herein to any specific commercial product, process, or service by trade name, trademark, manufacturer, or otherwise does not necessarily constitute or imply its endorsement, recommendation, or favoring by the United States Government or any agency thereof. The views and opinions of authors expressed herein do not necessarily state or reflect those of the United States Government or any agency thereof.”
\end{abstract}




\begin{abstract}
The Chemical Flooding process, like a polymer treatment, as a tertiary (enhanced) oil recovery process can be a very good solution based on the condition of this field and its low cost compared to the drilling of new wells. It is an improved water flooding method in which high molecular-weight (macro-size molecules) and water-soluble polymers are added to the injection water to improve the mobility ratio by enhancing the viscosity of the water and by reducing permeability in invaded zones during the process. In other words, it can improve the sweep efficiency by reducing the water mobility. This polymer treatment can be performed on the same active oil producer well rather than on an injector well in the existence of strong water drive in the formation. Some parameters must be considered before any polymer job is performed such as: formation temperature, permeability, oil gravity and viscosity, location and formation thickness of the well, amount of remaining recoverable oil, fluid levels, well productivity, water oil ratio (WOR) and existence of water drive. This improved oil recovery technique has been used widely and has significant potential to extend reservoir life by increasing the oil production and decreasing the water cut. This new technology has the greatest potential in reservoirs that are moderately heterogeneous, contain moderately viscous oils, and have adverse water-oil mobility ratios. For example, many wells in Kansas's Arbuckle formation had similar treatments and we have seen very effective results. In addition, there were previous polymer treatments conducted by Texaco in Alameda Field on a number of wells throughout the Viola-Simpson formation in the early 70's. Most of the treatments proved to be very successful.
\end{abstract}




\section{Table of Contents}

List of Graphical Materials $\quad 4$

Introduction 5

Executive Summary $\quad 8$

Experimental 9

Results and Discussion 10

Conclusion $\quad 11$

References $\quad 12$ 
List(s) of Graphical Materials

None 


\section{Introduction}

Alameda field is located in Kingman County, KS and has yielded approximately 1500 acres of production from the Viola-Simpson, Mississipian, and Lansing Kansas City rock formations. The Lansing Kansas City (LKC) reservoir in the Alameda field is limestone and has two productive porosity zones, which are the Lansing "L" which occurs at a log depth of $3362 \mathrm{ft}$. and a gross thickness of $30 \mathrm{ft}$. and the Lansing " $\mathrm{M}$ " which occurs at $3698 \mathrm{ft}$. and a gross thickness of $20 \mathrm{ft}$. The Viola-Simpson formation has symmetrical, anticlinal closure with a steeply dipping, faulted west flank. The Viola consists of a medium to coarse crystalline, vuggy dolomite and occurs at a depth of 4353 $\mathrm{ft}$. and a gross avg. thickness of $15 \mathrm{ft}$. The Simpson reservoir is a clear, medium grained, well-sorted, rounded and friable sandstone and occurs at a depth of $4356 \mathrm{ft}$. with gross thickness of $20 \mathrm{ft}$. The porosity of the LKC formation ranges from $16 \%$ to $20 \%$ and permeability ranging from 35 to $119 \mathrm{md}$. The porosity of the Viola-Simpson formation ranges from $13 \%$ to $17 \%$ with permeability of 12 to $169 \mathrm{md}$.

Alameda field has about 22.2 MM res bbl of oil originally stored in the Lansing Kansas City and Viola-Simpson formations. On the other hand, the Mississipian formation produces mainly gas. The total field production per year has declined from 189,956 bbls in 1966 to 13,437 bbls in 2001. The field cumulative production reached $9,525,803$ bbls in 2002 . This results in a total estimated recovery factor of close to $49 \%$ based on the avg. initial oil formation factor, $\mathrm{Bo}_{\mathrm{i}}$, of $1.5 \mathrm{res} \mathrm{bbl} / \mathrm{STB}$ which is found based on the type of oil produced and from literature. The main issue encountered with this field is the reduced oil production with a huge increase in water cut due to channeling in the bottom water drive reservoir. This gives an indication that the formation has large permeability variations, which causes oil to remain in the less permeable regions whereas the most permeable areas are yielding $100 \%$ water.

The Chemical Flooding process, like a polymer treatment, as a tertiary (enhanced) oil recovery process can be a very good solution based on the condition of this field and its low cost compared to the drilling of new wells. It is an improved water flooding method in which high molecular-weight (macro-size molecules) and water-soluble polymers are added to the injection water to improve the mobility ratio by enhancing the viscosity of the water and by reducing permeability in invaded zones during the process. In other words, it can improve the sweep efficiency by reducing the water mobility. This polymer treatment can be performed on the same active oil producer well rather than on an injector well in the existence of strong water drive in the formation. Some parameters must be considered before any polymer job is performed such as: formation temperature, permeability, oil gravity and viscosity, location and formation thickness of the well, amount of remaining recoverable oil, fluid levels, well productivity, water oil ratio (WOR) and existence of water drive. This improved oil recovery technique has been used widely and has significant potential to extend reservoir life by increasing the oil production and decreasing the water cut. This new technology has the greatest potential in reservoirs that are moderately heterogeneous, contain moderately viscous oils, and have adverse water-oil mobility ratios. For example, many wells in Kansas's Arbuckle formation had similar treatments and we have seen very effective results. In addition, there were previous polymer treatments conducted by Texaco in Alameda Field on a 
number of wells throughout the Viola-Simpson formation in the early 70's. Most of the treatments proved to be very successful.

The polymer treatment used in the early 70's is now old technology. Many developments have been made to improve polymer stability by using a new modified type of synthetic polymer and gel, which aids in recovery percentages. The new polymer and treatment technologies have indicated that significant amounts of new reserves are being added in mature producing basins.

Based on the data for this field and on the information obtained from other polymer treatments, the LKC and Viola-Simpson formations are 0excellent candidates for polymer jobs. The new polymer treatment will apply new modified gel, which is comprised of two chemicals: a dry polyacrylamide polymer and chromic acetate as the cross-linker. The polymer is mixed in water and the cross-linker is then added. This product is a high strength gel that is insensitive to any reservoir issues such as H2S, salinity, ph levels, and temperature. This type of gel has been used in Kansas's Arbuckle formation and showed huge success. This new technology procedure includes first cleaning the wellbore using acid then pumping it away with water followed by pumping in a polymer gel mixed with water. The final stage is to flush the zone with oil or water to clear up the near wellbore, freeing up the high conductivity flow paths, followed by shutting in the well for 4-5 days to assure maximum development of gel strength. The average cost of a polymer treatment per well is around $\$ 60,000$ which includes water, acid, polymer and crosslinker, flush oil, pump, data acquisition unit and mobile laboratory, workover and rig cost. The benefits of the project will be in terms of finding additional oil reserves created by reducing the lifting cost from over $\$ 20 /$ bbl to below $\$ 12 /$ bbl of oil produced. Another expected result will be the extension of the life of this field and increased reserve recovery.

The company is planning to perform the procedure on three wells with an estimated cost of $\$ 60,000$ per well. The following is an estimated work schedule:

\begin{tabular}{|l|l|l|l|}
\hline Date & Work Description & Duration & Comments \\
\hline Jan 03 & Alameda\#1 treatment & 5-6 days & Evaluate 30-60 days and design next treatment \\
\hline Feb-Mar 03 & Alameda\#2 treatment & 5-6 days & Evaluate 30-60 days and design next treatment \\
\hline $\begin{array}{l}\text { Mar-Apr } \\
03\end{array}$ & Alameda\#3 treatment & 5-6 days & $\begin{array}{l}\text { Evaluate and report program results inclusive } \\
\text { of 30, 60 and 90 days responses to treatment }\end{array}$ \\
\hline Jun 03 & $\begin{array}{l}\text { Analysis and results } \\
\text { report }\end{array}$ & $\begin{array}{l}\text { Evaluate until Jun 03 for final program } \\
\text { analysis }\end{array}$ \\
\hline
\end{tabular}

High water cut prevents small companies from producing oil due to excessive water handling cost. Therefore, the objective is to apply and see the effect of the new milestone technology (dry polyacrylamide polymer and chromic acetate as the crosslinker) in the Viola-Simpson and the Lansing Kansas City formations in Alameda field. The desired effect is to find additional reserves, thereby increasing production while reducing water production and lifting cost by using polymer treatments on active producing wells. Alameda field is in danger of being abandoned even though one-fourth to one-half of the 9.00 MMSTB (movable oil left) has yet to be recovered. Therefore, Crystal River Oil and Gas, LLC is hopeful to participate in the following class revisit program: "Technology Development with Independents" which is provided by The Department of Energy (DOE), National Energy Technology Laboratory (NETL), on 
behalf of the National Petroleum Technology Office (NPTO) for the research benefits from the technologies and successes demonstrated in the original class program and apply those with new technologies. With program funding, support and the use of these new technologies, this field can be brought back to economic life again and prevent further loss of access to our Nation's valuable oil reserves. 


\section{Executive Summary}

The first polymer job in the Alameda Field on Well 5-3 was conducted in July 2003, after well preparation and operations from January 2003 until July 2003. Results have not indicated any significant improvement in oil recoveries. In fact, it may appear that the polymer job has negatively impacted the productive formation in and around the wellbore of the Alameda 5-3 well. 


\section{Experimental}

No Discussion 


\section{Results and Discussion}

The first polymer job in the Alameda Field on Well 5-3 was conducted in July 2003, after well preparation and operations from January 2003 until July 2003. Results have not indicated any significant improvement in oil recoveries. In fact, it may appear that the polymer job has negatively impacted the productive formation in and around the wellbore of the Alameda 5-3 well. 


\section{Conclusion}

The first polymer job in the Alameda Field on Well 5-3 was conducted in July 2003, after well preparation and operations from January 2003 until July 2003. Results have not indicated any significant improvement in oil recoveries. In fact, it may appear that the polymer job has negatively impacted the productive formation in and around the wellbore of the Alameda 5-3 well.

No further polymer jobs were done under this contract. 


\section{References}

None 